\title{
Optimization of Ionic Liquid Based Simultaneous Ultrasonic- and Microwave-Assisted Extraction of Rutin and Quercetin from Leaves of Velvetleaf (Abutilon theophrasti) by Response Surface Methodology
}

\author{
Chunjian Zhao, ${ }^{1,2}$ Zhicheng Lu, ${ }^{2}$ Chunying Li, ${ }^{2} \mathrm{Xin} \mathrm{He}^{2} \mathrm{Zhao} \mathrm{Li}^{2}$ \\ Kunming Shi, ${ }^{2}$ Lei Yang, ${ }^{2}$ Yujie $\mathrm{Fu}^{2}$ and Yuangang $\mathrm{Zu}^{2}$ \\ ${ }^{1}$ College of Resources and Environmental Sciences, China Agricultural University, Beijing 100193, China \\ ${ }^{2}$ Key Laboratory of Forest Plant Ecology, Ministry of Education, Northeast Forestry University, Harbin 150040, China
}

Correspondence should be addressed to Chunying Li; nefujane@aliyun.com

Received 3 July 2014; Accepted 5 August 2014; Published 27 August 2014

Academic Editor: Fred Stevens

Copyright (C) 2014 Chunjian Zhao et al. This is an open access article distributed under the Creative Commons Attribution License, which permits unrestricted use, distribution, and reproduction in any medium, provided the original work is properly cited.

\begin{abstract}
An ionic liquids based simultaneous ultrasonic and microwave assisted extraction (ILs-UMAE) method has been proposed for the extraction of rutin (RU), quercetin (QU), from velvetleaf leaves. The influential parameters of the ILs-UMAE were optimized by the single factor and the central composite design (CCD) experiments. A 2.00 M 1-butyl-3-methylimidazolium bromide $([\mathrm{C} 4 \mathrm{mim}] \mathrm{Br})$ was used as the experimental ionic liquid, extraction temperature $60^{\circ} \mathrm{C}$, extraction time 12 min, liquid-solid ratio $32 \mathrm{~mL} / \mathrm{g}$, microwave power of $534 \mathrm{~W}$, and a fixed ultrasonic power of $50 \mathrm{~W}$. Compared to conventional heating reflux extraction (HRE), the RU and QU extraction yields obtained by ILs-UMAE were, respectively, $5.49 \mathrm{mg} / \mathrm{g}$ and $0.27 \mathrm{mg} / \mathrm{g}$, which increased, respectively, 2.01-fold and 2.34-fold with the recoveries that were in the range of 97.62-102.36\% for RU and 97.33-102.21\% for QU with RSDs lower than 3.2\% under the optimized UMAE conditions. In addition, the shorter extraction time was used in ILs-UMAE, compared with HRE. Therefore, ILs-UMAE was a rapid and an efficient method for the extraction of RU and QU from the leaves of velvetleaf.
\end{abstract}

\section{Introduction}

Velvetleaf (Abutilon theophrasti Medik) is one of the main members in Malvaceae and it is a major annual weed in cropland [1]. There are lots of biological activity components in leaves and seeds from velvetleaf $[2,3]$. However, there is less information about velvetleaf flavonoids components $[4,5]$. It was reported that there were flavonoids in velvetleaf and the main three components were rutin (RU), quercetin (QU), and kaempferol (KA) [4, 6]. Our preliminary study showed that there were rich RU and QU, but a little KA from Chinese velvetleaf.

RU (3,4,5,7-tetrahydroxyflavone-3-d-rutinoside) and QU (3,3', $4^{\prime}, 5,7$-pentahydroxyflavone), whose structures are shown in Figure 1, are two effective compounds for curing hypertension, diabetes, and cardiac and cerebral vascular diseases [7-9]. In addition, they display the activities of antioxidant [10-12], anti-inflammatory [13, 14], antimicrobial [15], antitumor [16], and antiasthma [17]. In virtue of the above important activities of RU and QU and their plentiful content in velvetleaf, therefore, it is very important to develop a method for the extraction and determination of RU and QU from velvetleaf in order to utilize the abundant velvetleaf resources in China.

Conventional heating reflux extraction (HRE) and ultrasonic extraction (UE) were once applied in the extraction of flavonoids [18]. However, these extraction processes are connected with long extraction time and unsatisfactory recovery. Thus, it is desirable to develop a rapid and efficient extraction method to improve the limitations of conventional extraction of flavonoids [19].

Ionic liquids (ILs) are a kind of salts that display an amazingly lower melting temperature than the boiling point of water and they are often liquid at room temperature. 


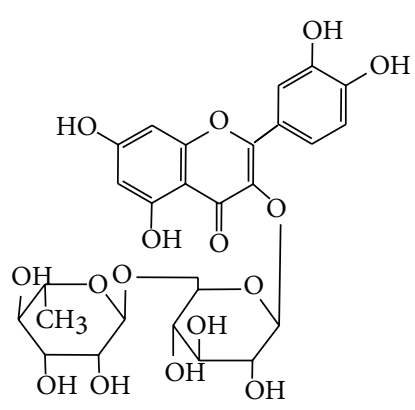

Rutin<smiles>O=c1c(O)c(-c2ccc(O)c(O)c2)oc2cc(O)cc(O)c12</smiles>

Quercetin
FIgURE 1: Chemical structures of rutin (RU) and quercetin (QU).

ILs constituted of relatively large asymmetric organic cations and smaller inorganic or organic anions [20]. Due to their negligible vapor pressure, good thermal sensibility, low or virtually no volatility, good miscibility with water and organic solvents, and extractability for various organic compounds, they have recently been widely applied in the extraction and separation from natural product [21-23]. For example, different types of compounds such as essential oils, flavonoids, suberin, polyphenolic compounds, and alkaloids were all extracted by many ILs-based extraction technologies [2426].

In recent times, microwave-assisted extraction (MAE) has been rapidly developed and proposed as a prospective and influential technique to replace conventional extraction techniques in the extraction of bioactive constituents from plant materials because of its special heating mechanism, moderate capital cost, rapid extraction, and excellent performance [27, 28]. It has been reported that microwave energy can be efficiently absorbed under the ILs as solvents and cosolvents conditions [29]. Considering that ILs can efficiently absorb microwave energy, it is rather an interesting challenge to use ILs as solvent for the MAE of various biomolecules from solid samples. Comparing with conventional organic solvents, ILs are green solvents because their vapour pressure was so lower that ILs are very difficult to evaporate into the environment. In some cases, they could even be well recycled. They can effectively improve the selectivity and the extraction efficiency of the being investigated compounds from plant samples [29].

Ultrasonic is one of the most industrially used methods to enhance the extraction effects due to its mass transfer phenomena [30-32]. Recently, simultaneous ultrasonic/microwave assisted extraction (UMAE) coupled the advantage of microwave and ultrasonic, presenting many advantages [33, 34]. However, there are no reports on ILs-based simultaneous ultrasonic and microwave assisted extraction (ILs-UMAE) of RU and QU from leaves of velvetleaf.

In the present study, a fast and efficient method of ILsUMAE separation and determination of two major flavones (RU and QU) from leaves of velvetleaf was developed and the effects of extraction time, temperature, ionic liquids concentration, solid-liquid ratio, and microwave power on
RU and QU yields were investigated and further optimized by a central composite design (CCD) and response surface methodology (RSM).

\section{Experimental}

2.1. Chemicals and Reagents. RU and QU standards were bought from J \& K Chemical Ltd. (Beijing, China). All ionic liquids $([\mathrm{C} 2 \mathrm{mim}] \mathrm{Br}$, 1-ethyl-3-methylimidazolium bromide; [C4mim]Br, 1-butyl-3-methylimidazolium bromide; [C6mim]Br, 1-hexyl-3-methylimidazolium bromide; [C8mim]Br, 1-octyl-3-methylimidazolium bromide; [C4mim] Cl, [C4mim]NO3, [C4mim]HSO4, [C4mim]BF4, [C4mim], that is 1-octyl-3-methylimidazolium bromide) were purchased from J \& K Chemical Ltd. (Beijing, China). Deionized water for HPLC was purified using a Milli-Q Water Purification System (Millipore, MA, USA). Other analytical reagents were purchased from the Tianjin Kermel Chemical Reagent Co. Ltd. (Tianjin, China).

2.2. Materials. The leaves of velvetleaf were collected in autumn from Shuyang County, Jiangsu, China. Voucher specimens were deposited in the herbarium of our laboratory. The materials were dried in the shade at room temperature, powdered by a disintegrator (HX-200A, Yongkang Hardware and Medical Instrument Plant, China), and passed through a stainless steel sieve (40-60 mesh) and stored in closed desiccators at $4^{\circ} \mathrm{C}$ until use.

2.3. Apparatus. Simultaneous ultrasonic and microwave extracting apparatus (CW-2000, Shanghai Xintuo analytical instrument technology Co. Ltd., China, the maximum power of $700 \mathrm{~W}$ and a fixed ultrasonic power of $50 \mathrm{~W}$ ) and ultrasonic extraction device (A KQ-250DB, Kunshan, China) with a maximum power of $250 \mathrm{~W}$ were used for the extraction of targets compounds. The HPLC system consisted of a Waters 717 automatic sample handling system series HPLC system equipped with a 1525 pump, a 717 automatic column temperature control box, and a 2487 UV-detector (Waters, USA) that was used for the determination of targets compounds. Chromatographic separation was performed on a HiQ silC18 reversed-phase column $(4.6 \mathrm{~mm} \times 250 \mathrm{~mm}, 5 \mathrm{~m}, \mathrm{KYA}$ $\mathrm{TECH})$.

\subsection{Extraction Methods}

2.4.1. Heating Reflux Extraction (HRE). A $1.0 \mathrm{~g}$ of dried sample powders was put into a round-bottomed flask by adding $20 \mathrm{~mL}$ of methanol or $2 \mathrm{M}$ [C4mim] Br; then the flask was placed into oil bath with a reflux device, followed by extracting at $6 \mathrm{~h}$.

2.4.2. Ultrasonic-Assisted Extraction (UAE). A $1.0 \mathrm{~g}$ of dried sample powders was put into a conical flask by adding $20 \mathrm{~mL}$ of methanol or $2 \mathrm{M}[\mathrm{C} 4 \mathrm{mim}] \mathrm{Br}$; then the conical flask was placed into the ultrasonic extraction device, followed by sonication for $1 \mathrm{~h}$ at room temperature. 


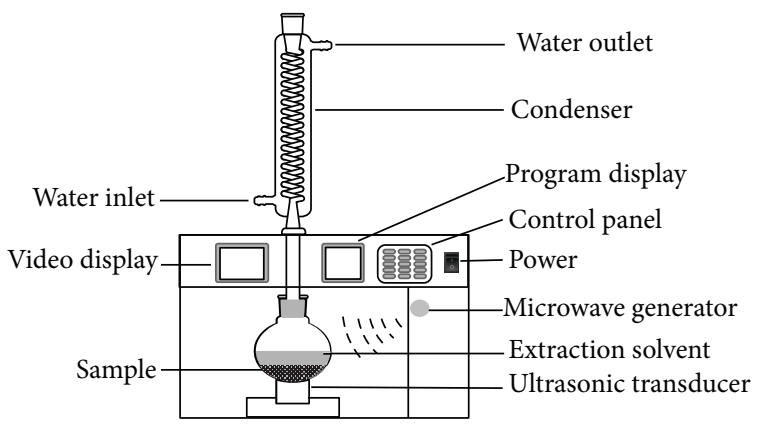

FIgURE 2: Schematic representation of the UMAE device.

2.4.3. Microwave-Assisted Extraction (MAE). A $1.0 \mathrm{~g}$ of dried sample powders was put into a special round-bottomed flask by adding $20 \mathrm{~mL}$ of methanol or $2 \mathrm{M}$ [C4mim] Br; then the round-bottomed flask was placed into the pressure self-control microwave decomposition system followed by microwave irradiation.

2.4.4. Ultrasonic- and Microwave-Assisted Extraction (ILUMAE). UMAE device was used to separate RU and QU from the leaves of velvetleaf. The apparatus is shown schematically in Figure 2. With cold water running through the condenser of the UMAE system, sample was mixed with methanol or different concentrations of IL solutions, and then the suspensions were irradiated under microwave heating and a fixed ultrasonic power of $50 \mathrm{~W}$. After each irradiation, the obtained extracts were cooled to $25^{\circ} \mathrm{C}$, then diluted to $50 \mathrm{~mL}$ with water, and filtrated through a $0.45-\mu \mathrm{m}$ filter for subsequent HPLC analysis.

2.5. Determination of $R U$ and $Q U$ by HPLC. The diluted extracts were directly injected into the system which was a Waters 717 automatic sample handling system series HPLC system. The conditions of HPLC analysis were as follows: the mobile phase was methanol-acetonitrile-water $(40: 15: 45$, $\mathrm{v} / \mathrm{v} / \mathrm{v}$ ) adding $1.0 \%$ acetic acid. This mobile phase was filtered through a $0.45 \mu \mathrm{m}$ membrane filter and then deaerated ultrasonically prior to use. The injection volume was $10 \mu \mathrm{L}$ and the column temperature was set at $25^{\circ} \mathrm{C}$. The flow rate was $1 \mathrm{~mL} / \mathrm{min}$. The UV detection wavelength applied was $360 \mathrm{~nm}$. Peak areas of RU and QU were used for quantification with external standard method.

The extraction yield of target analyte was determined as follows:

$$
\begin{aligned}
\text { Yield }(\mathrm{mg} / \mathrm{g}) & \\
= & \frac{\text { mean mass of target analytes in sample }(\mathrm{mg})}{\text { mass of samples }(\mathrm{g})} .
\end{aligned}
$$

The mean mass of target analytes in samples was calculated after 3 repeated determinations under the optimized conditions.
2.6. Experimental Design. First, the influencing factors of ILs-UMAE, namely, extraction time, temperature, ionic liquids concentration, solid-liquid ratio, and microwave power on the yields of RU and QU were investigated. On the above single factor experiments, the three dominating parameters, that is, microwave power, extraction time, and liquid-solid ratio on the yields of RU and QU, were optimized by RSM. In detail, the effects of three independent variables including extraction time (X1: 6-14 min), liquid-solid ratio (X2: 20$40 \mathrm{~mL} / \mathrm{g}$ ), and microwave power (X3: $300-700 \mathrm{~W}$ ) at five levels $(-1.68,-1,0,+1,+1.68)$ were investigated using a central composite design (CCD) with RSM (Table 1).

A total of 20 experiments consisting of 8 factorial points, 6 axial points, and 6 replicates at the central points were performed. Experimental data collected from the designed experiment were analyzed by a response surface regression model using the following second-order polynomial:

$$
Y=\beta_{0}+\sum_{i=1}^{3} \beta_{i} X_{i}+\sum_{i=1}^{3} \beta_{i i} X_{i}^{2}+\sum_{\substack{i=1 \\ i<j}}^{2} \sum_{j=2}^{3} \beta_{i j} X_{i} X_{j},
$$

where $Y$ represented the response variable; $\beta_{0}, \beta_{i}, \beta_{i i}$, and $\beta_{i j}$ were the regression coefficients of variables for intercept, linearity, square, and interaction terms, respectively; $X_{i}$ and $X_{j}$ were the independent coded variables influencing the response variable $Y$; and $k$ represents the number of variables.

2.7. Statistical Analysis. Design Expert (DE) software (Trial version 7.0.0, STAT-EASE Inc., Minneapolis, MN, USA) was used to analyze the experimental data and to find the response surfaces of the response models and it was used to decide and assess the statistical significance of the equations. The lack of fit and coefficient of determination $\left(R^{2}\right)$ were used to evaluate the adequacy of model. The Fisher test value ( $F$-value) and their interactions were estimated by the analysis of variance (ANOVA). Finally, in order to decide the adequacy of the fitted model, the actual and predicted values were compared.

The optimum condition for three variables (extraction time: 6-14 min, liquid-solid ratio: $20-40 \mathrm{~mL} / \mathrm{g}$, and microwave power: $300-700 \mathrm{~W}$ ) was acquired by statistical analysis (DE software) [35].

\section{Results and Discussion}

\subsection{Selection of ILs for UMAE}

3.1.1. Effect of Anion. The anion identity is an important factor to impact the properties of ILs [36]. Thus, the 1-butyl-3methylimidazolium ILs with five kinds of different anions $\left(\mathrm{Br}^{-}, \mathrm{Cl}^{-}, \mathrm{NO}_{3}{ }^{-}, \mathrm{HSO}_{4}^{-}\right.$, and $\left.\mathrm{BF}_{4}^{-}\right)$were selected in UMAE. As shown in Figure 3(a), compared with the extraction results using five different types of $1 \mathrm{M}$ ILs solutions with the same cations but different anions, it was apparently found that [C4mim] Br was more efficient than others.

It was probably due to the stronger multi-interactions including $\pi-\pi$, ionic/charge - charge, and hydrogen bonding between the ILs ([C4MIM]Br) and flavonoids [33]. 
TABLE 1: Central composite design (CCD) of independent variables for process optimization.

\begin{tabular}{|c|c|c|c|c|c|c|}
\hline \multirow[b]{2}{*}{ Run } & \multicolumn{3}{|c|}{ Coded } & \multicolumn{3}{|c|}{ Actual } \\
\hline & $\begin{array}{c}\text { Factor A } \\
\left(X_{1}\right)\end{array}$ & $\begin{array}{c}\text { Factor B } \\
\left(X_{2}\right)\end{array}$ & $\begin{array}{c}\text { Factor C } \\
\left(X_{3}\right)\end{array}$ & $\begin{array}{c}\text { Time, } \\
\min \left(X_{1}\right)\end{array}$ & $\begin{array}{c}\text { Liquid-solid ratio, } \\
\mathrm{mL} / \mathrm{g}\left(X_{2}\right)\end{array}$ & $\begin{array}{c}\text { Microwave power, } \\
\mathrm{W}\left(X_{3}\right)\end{array}$ \\
\hline 1 & 1 & -1 & 1 & 14 & 20 & 700 \\
\hline 2 & -1 & -1 & 1 & 6 & 20 & 700 \\
\hline 3 & 0 & 0 & 0 & 10 & 30 & 500 \\
\hline 4 & -1 & 1 & 1 & 6 & 40 & 700 \\
\hline 5 & 0 & 0 & 1.68 & 10 & 30 & 836.36 \\
\hline 6 & 1.68 & 0 & 0 & 16.73 & 30 & 500 \\
\hline 7 & 1 & 1 & 1 & 14 & 40 & 700 \\
\hline 8 & 0 & 0 & 0 & 10 & 30 & 500 \\
\hline 9 & -1 & -1 & -1 & 6 & 20 & 300 \\
\hline 10 & 1 & 1 & -1 & 14 & 40 & 300 \\
\hline 11 & 0 & 0 & 0 & 10 & 30 & 500 \\
\hline 12 & 0 & 0 & -1.68 & 10 & 30 & 163.64 \\
\hline 13 & -1 & 1 & -1 & 6 & 40 & 300 \\
\hline 14 & 1 & -1 & -1 & 14 & 20 & 300 \\
\hline 15 & 0 & 0 & 0 & 10 & 30 & 500 \\
\hline 16 & 0 & 0 & 0 & 10 & 30 & 500 \\
\hline 17 & 0 & -1.68 & 0 & 10 & 13.18 & 500 \\
\hline 18 & 0 & 0 & 0 & 10 & 30 & 500 \\
\hline 19 & 0 & 1.68 & 0 & 10 & 46.82 & 500 \\
\hline 20 & -1.68 & 0 & 0 & 3.27 & 30 & 500 \\
\hline
\end{tabular}

3.1.2. Effect of the Alkyl Chain Length. The alkyl chain length of the imidazolium ring of ILs has a significant influence on their physical and chemical properties [37, 38]; thus, the alkyl chain length of ILs will consequently influence the extraction yields of the analytes. In order to investigate the effect of 1-alkyl-3-methylimidazolium-type ILs, ILs with different alkyl chain lengths of cation on the extraction yields of RU and QU were studied in UMAE process. The four kinds of ILs were investigated in UMAE, that is, $[\mathrm{C} 2 \mathrm{mim}] \mathrm{Br}$, 1-ethyl-3-methylimidazolium bromide; [C4mim]Br, 1butyl-3-methylimidazolium bromide; [C6mim]Br, 1-hexyl3-methylimidazolium bromide; [C8mim]Br, 1-octyl-3methylimidazolium bromide. Water and different types of $1 \mathrm{M}$ ILs solution were used for the extraction solvents for assessing the extraction yield of RU and QU in UMAE procedure. The results are shown in Figure 3(b), ILs with different alkyl chain lengths of cation significantly influenced the extraction yields of target compounds, and obviously, while $[\mathrm{C} 4 \mathrm{mim}] \mathrm{Br}$ was used as extraction solvent, the higher extraction yields of RU and QU were obtained than the other three ILs. Compared with the other ILs solutions, water as the solvent, the extraction yields of RU and QU were the most poor. The possible reason was related to the solubility of flavonoids compounds in extraction solvent. The addition of ILs solution improved the extraction yields of target compounds; it may be the reason that the strong dissolvable ability of ILs on target compounds [39-41]. When, the alkyl chain length was more than 4 carbons, the extraction yield of RU and QU distinctly decreased in
ILs-UMAE process. Therefore, [C4mim] Br was selected for the further experiments.

\subsection{Optimization of IL-UMAE Conditions}

3.2.1. Single Factor Experiments. Single factor experiment was performed by one factor varied with different levels, while other factors were fixed. There are many factors affecting the extraction yields of target compounds, which involved the concentration of [C4mim]Br solution, extraction time, liquid-solid ratio, extraction temperature, and microwave power. All results of single factor experiments were shown in Figure 4.

In Figure 4, it can be apparently observed that when the concentration of $[\mathrm{C} 4 \mathrm{mim}] \mathrm{Br}$ solution was $2 \mathrm{M}$, the extraction yield of RU and QU was the highest. While the concentration of $[\mathrm{C} 4 \mathrm{mim}] \mathrm{Br}$ solution was less than $2 \mathrm{M}$, the extraction yields of target compounds increased rapidly, which might be the reason, with the increasing of [C4mim] Br, both the solubility and the extracting capacity of the solvent were enhanced. At the same time, the capabilities of microwave absorption and microwave conversion were both increased. However, when the concentration of [C4mim]Br solution was more than $2 \mathrm{M}$, the extraction yields declined. The major cause was that the greater the $[\mathrm{C} 4 \mathrm{mim}] \mathrm{Br}$ concentration can severely influence the viscosity and the diffusion capacity of solutions. So $2 \mathrm{M}$ of [C4mim] Br was selected for further experiments. 


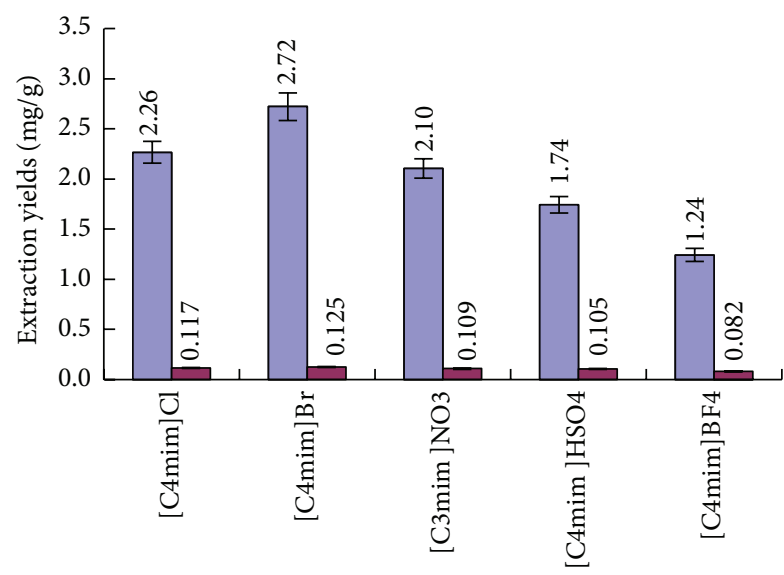

Extraction solvents

Rutin

Quercetin

(a)

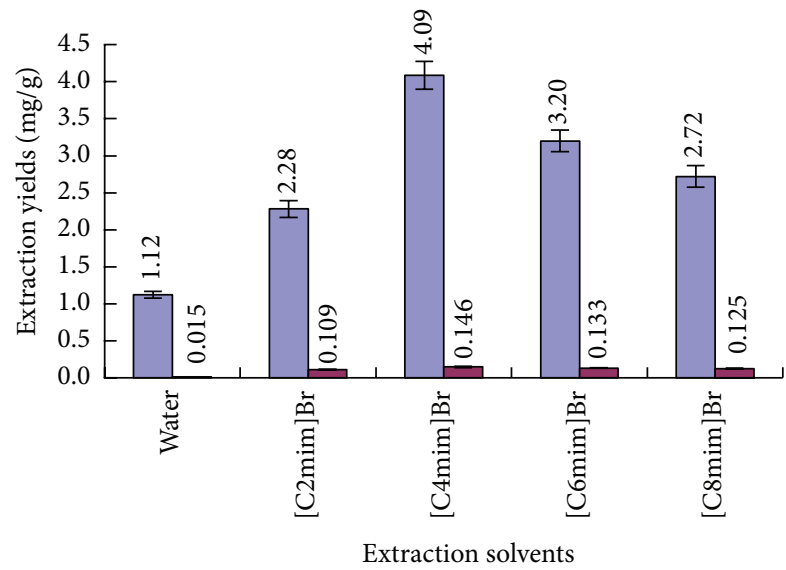

Rutin

Quercetin

(b)

FIGURE 3: Effect of ionic liquids anions (a) and cations (b) on the extraction yields of RU and QU. Error bars indicate standard deviation $(n=3)$.

The extraction time is another crucial factor that should be studied to increase the extraction yields of RU and QU. As shown in Figure 4, when the extraction time increased from 6 to $10 \mathrm{~min}$, the extraction yields of the two target compounds increased dramatically. When the time variable was changed from $10 \mathrm{~min}$ to $14 \mathrm{~min}$, the extraction yields of the two target compounds reduced slightly. Therefore, $10 \mathrm{~min}$ was selected for further experiments.

As for liquid-solid ratio, Figure 4 shows that the extraction yield of two target compounds increased significantly when the liquid-solid ratio increased from $20: 1$ to $30: 1 \mathrm{~mL} / \mathrm{g}$. In certain range, raising the liquid-solid ratio can make sample completely immerse into solvent and increase the mass transfer, and it results in the higher extraction yields of target compounds. Furthermore, with the increase of

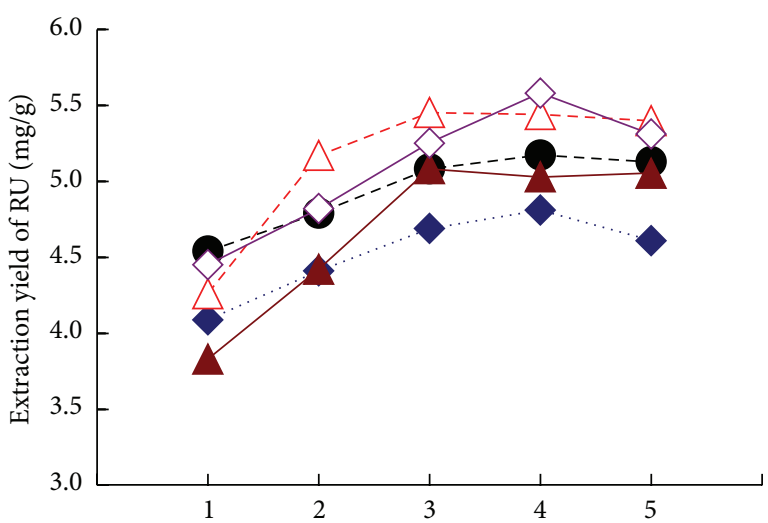

(a)

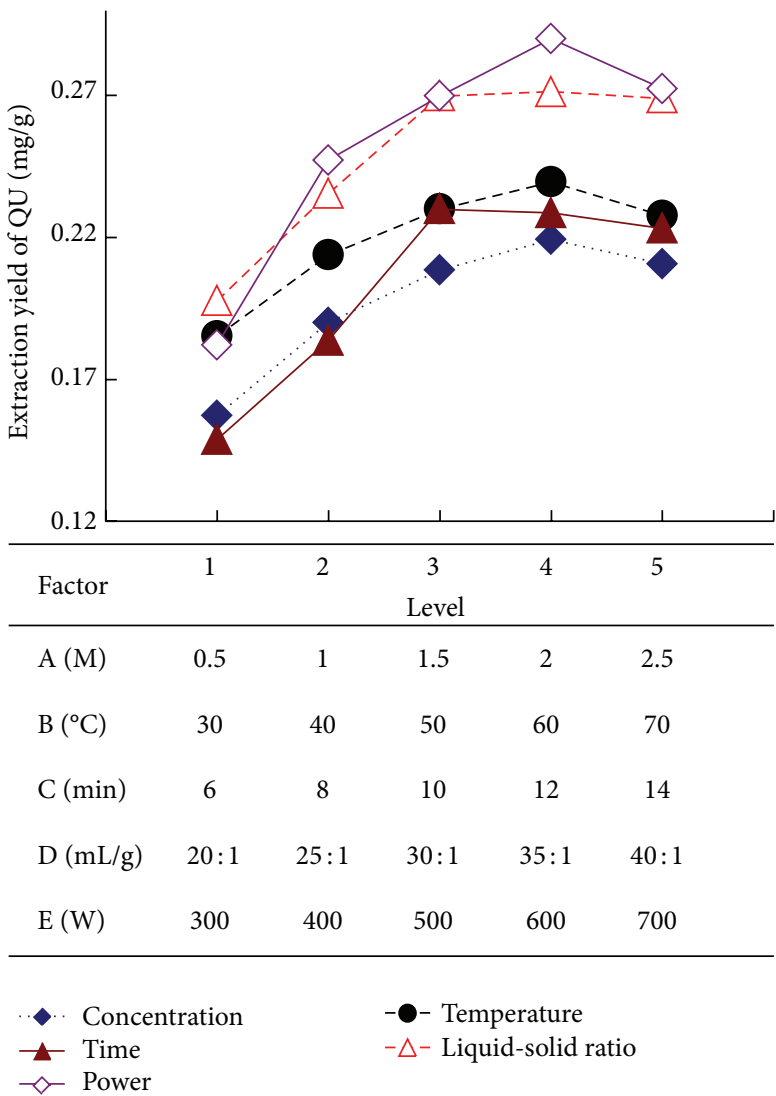

(b)

FIgURE 4: The effect of the concentrations of [C4mim]Br (A), extraction temperature (B), extraction time (C), liquid-solid ratio (D), and microwave power (E) on the extraction yields of RU and QU.

liquid-solid ratio from $30: 1$ to $40: 1 \mathrm{~mL} / \mathrm{g}$, the extraction yields of RU and QU no longer increased. Hence, $30: 1 \mathrm{~mL} / \mathrm{g}$ of liquid-solid ratio was selected for further experiments.

As shown in Figure 4, it can be seen that the extraction yields of RU and QU increased with the increase of the extracting temperature from $30-60^{\circ} \mathrm{C}$, which might be because the increasing of the extracting temperature contributes to reducing the viscosity of ILs and enhancing 
the spread ability and solubility of ILs, which was beneficial to dissolve and extract target compounds. However, when the temperature was higher than $60^{\circ} \mathrm{C}$, the extraction yield of RU and QU decreased slightly. The main reason may be the decomposition of some RU and QU at high temperature. Thus $60^{\circ} \mathrm{C}$ of temperature was selected for further experiments.

It can be shown from Figure 4 that with the increase of microwave power from 300 to $600 \mathrm{~W}$, the extraction yields of RU and QU increased rapidly. When the microwave power was higher than $600 \mathrm{~W}$, the extraction yields of RU and QU began to gradually decrease. Therefore, $600 \mathrm{~W}$ of power was selected for further experiments.

3.2.2. Statistical Analysis. The extraction time, liquid-solid ratio, and microwave power were selected as three independent factors, and the dependent variable (response, yields of RU and QU of each run of the experimental design) were investigated by RSM. In order to minimize the effects of the uncontrolled factors, the experimental sequence was randomized (see Table 1). The experimental results obtained at each point are shown in Table 2. These values of the significance of each experimental variable can be justified, which were made of the model fitted, the software generated model coefficients, $R^{2}$-values, Fit-values ( $F$-values), and significant probabilities. The response and variables were mutually fitted by multiple regressions. Regression analysis is the general approach to fit the empirical model with the collected response variable data [42]. The second-order polynomial model was generated to describe the empirical relationship between the yields of target compounds and operational conditions $\left(X_{1}\right.$ : extraction time, $X_{2}$ : liquid-solid ratio, and $X_{3}$ : microwave power) in terms of coded values:

$$
\begin{aligned}
Y_{1}= & 5.32+0.58 X_{1}+0.16 X_{2}+0.34 X_{3}-0.058 X_{1} X_{2} \\
& +0.029 X_{1} X_{3}-0.1 X_{2} X_{3}-0.48 X_{1}^{2}-0.24 X_{2}^{2}-0.27 X_{3}^{2}, \\
Y_{2}= & 0.26+0.029 X_{1}+0.016 X_{2}+8.322 \times 10^{-3} X_{3} \\
& -6.436 \times 10^{-3} X_{1} X_{2}+2.864 \times 10^{-3} X_{1} X_{3} \\
& -2.561 X_{2} X_{3}-0.026 X_{1}^{2}-0.024 X_{2}^{2}-0.010 X_{3}^{2} .
\end{aligned}
$$

The predicted values for extraction yield of RU and QU obtained using above model were seen in Table 2. The plot of actual values versus predicted values for the estimated model is shown Figure 5. The relationship between the actual and predicted values showed that the plotted points cluster around the diagonal line. Predicted $R^{2}$ are 0.9790 for extraction yield of RU and 0.9787 for extraction yield of QU, respectively; residual standard deviation (RSD) is $3.34 \%$ for extraction yield of RU and 3.92\% for extraction yield of QU, respectively.

Positive sign in model of each term represents synergistic effect, while antagonistic effect is represented by negative sign. Analysis of variance (ANOVA) was then used to assess the goodness of fit. The significant quadratic models and the corresponding significant model term for

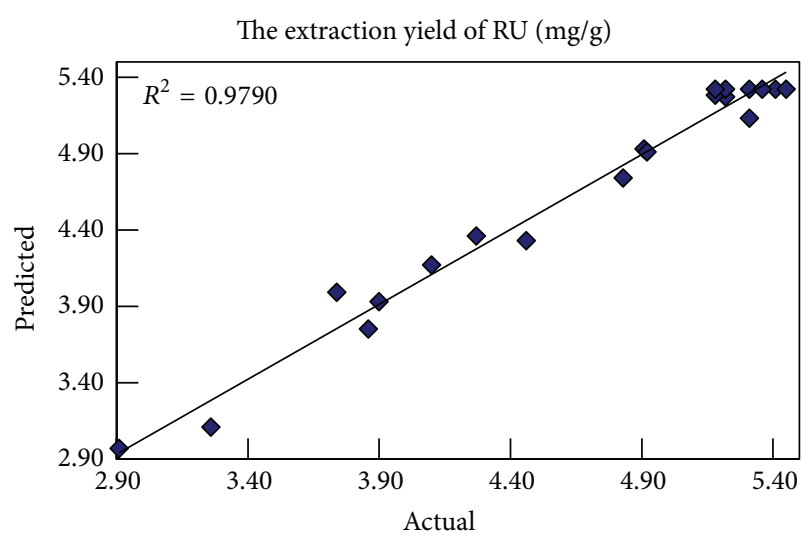

(a)

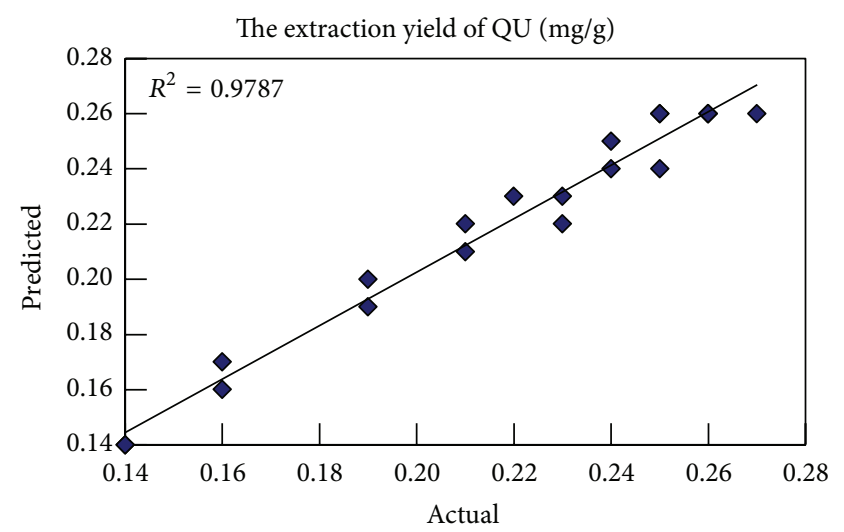

(b)

FIGURE 5: Actual versus predicted values obtained from estimated model.

all responses are tabulated in Table 3 for the extraction yield of RU and Table 4 for the extraction yield of QU, respectively.

In Table 3, the model $F$-value of 51.71 with a very low $P$ value $(P<0.0001)$ displayed that the generated model was statistically significant and indicated that the extraction yields of RU by IL-UMAE could be well described with this model. It was also observed that the linear term of extraction time $\left(X_{1}\right)$ and microwave power $\left(X_{3}\right)$ have large significant effect on the yield of RU because of the high $F$-value of 191.7 and 65.53 , respectively. The quadratic term of extraction time $\left(X_{1}^{2}\right)$ and microwave power $\left(X_{3}^{2}\right)$ are also significant with $F$-value of 143.34 and 43.04, respectively. According to the software analysis, the lack of fit $F$-value was 3.33 , and the $P$ value (0.1065) was greater than 0.05 indicating that the lack of fit was not significant relative to the pure error [43].

From Table 4 , the model $F$-value of 51.13 with a very low $P$ value $(P<0.0001)$ implies that the model is significant. It was clearly observed that extraction time $\left(X_{1}\right)$ and liquidsolid ratio $\left(X_{2}\right)$ have large significant effect on the yield of QU due to the high $F$-value of 158.99 and 45.26 , respectively. The quadratic term of extraction time $\left(X_{1}^{2}\right)$ and microwave power $\left(X_{2}^{2}\right)$ have also significant with $F$-value of 135.98 and 116.53, respectively. According to the software analysis, the lack of fit 


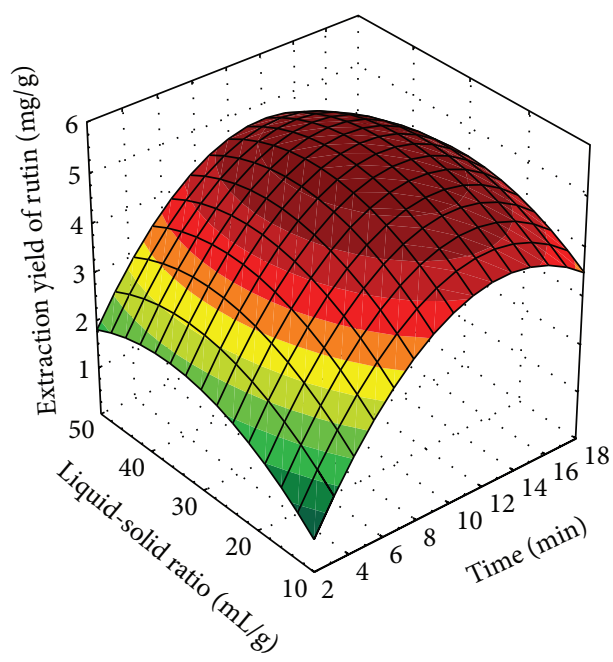

(a)

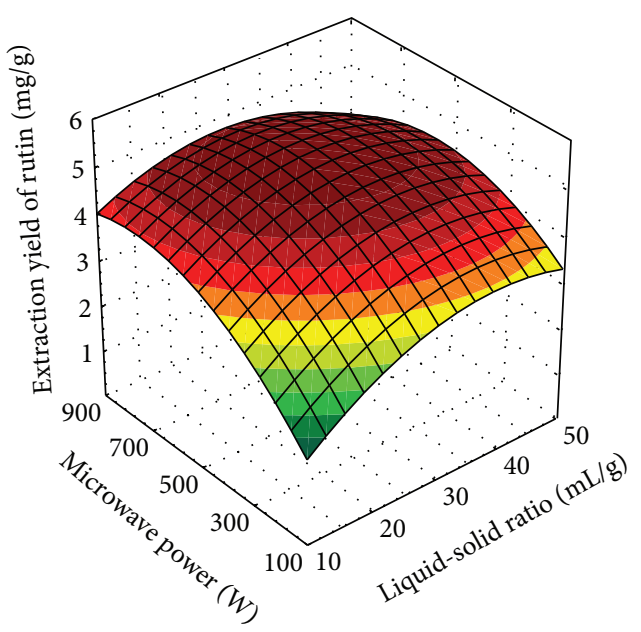

(c)

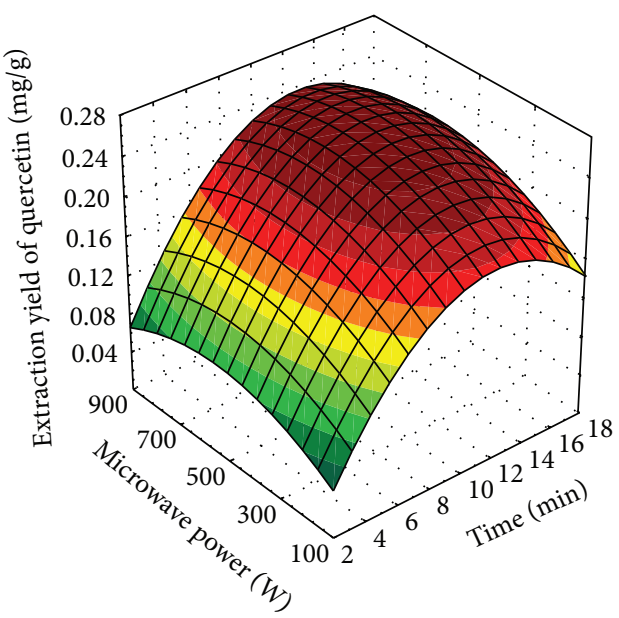

(e)

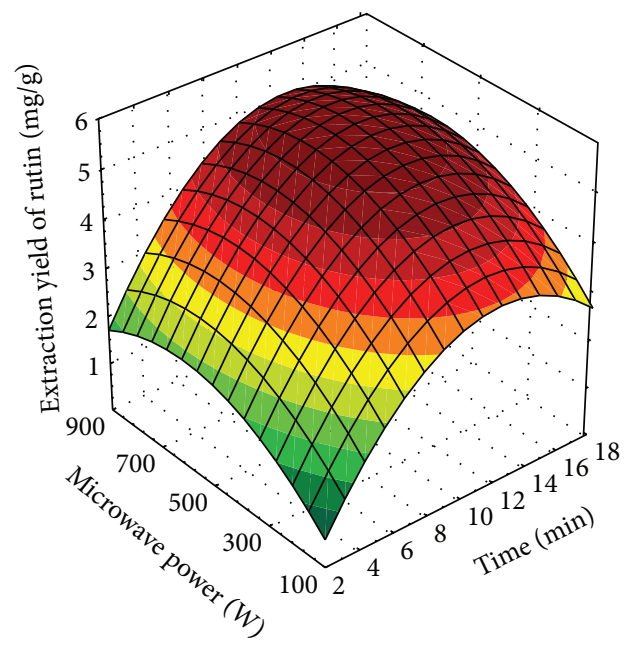

(b)

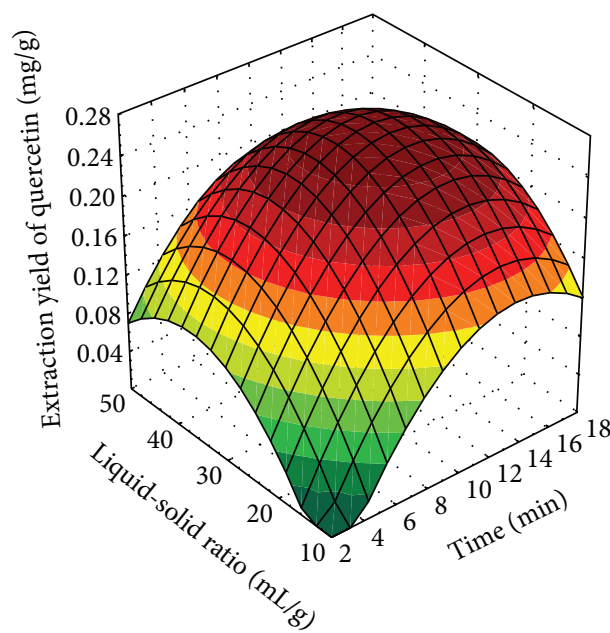

(d)

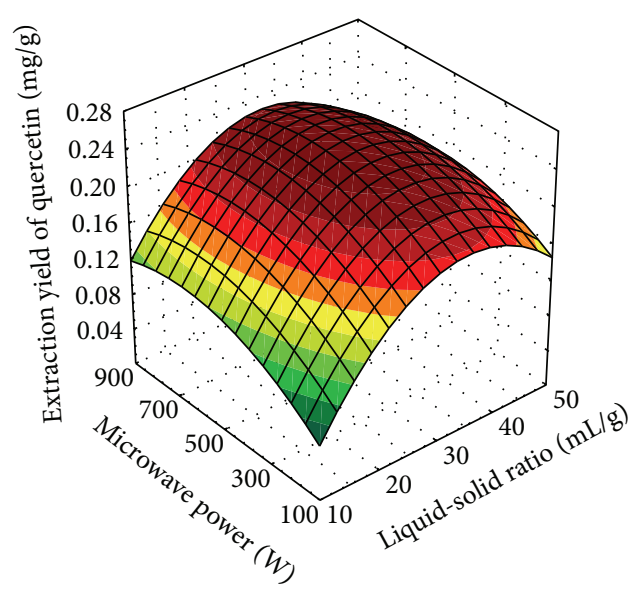

(f)

FIGURE 6: Response surface plots for extracting RU and QU by UMAE: (a) liquid-solid ratio and extraction time, (b) irradiation power and time, (c) irradiation power and liquid-solid ratio on yield of RU, (d) liquid-solid ratio and extraction time, (e) irradiation power and time, and (f) irradiation power and liquid-solid ratio on yield of QU. 
TABLE 2: Actual and predicted results for the extraction yields of RU and QU.

\begin{tabular}{|c|c|c|c|c|}
\hline \multirow[b]{2}{*}{ Run } & \multicolumn{2}{|c|}{ Actual values } & \multicolumn{2}{|c|}{ Predicted values } \\
\hline & $\begin{array}{c}\text { The extraction yield of RU } \\
(\mathrm{mg} / \mathrm{g})\end{array}$ & $\begin{array}{c}\text { The extraction yield of QU } \\
(\mathrm{mg} / \mathrm{g})\end{array}$ & $\begin{array}{l}\text { The extraction yield of RU } \\
(\mathrm{mg} / \mathrm{g})\end{array}$ & $\begin{array}{c}\text { The extraction yield of QU } \\
(\mathrm{mg} / \mathrm{g})\end{array}$ \\
\hline 1 & 5.22 & 0.23 & 5.27 & 0.23 \\
\hline 2 & 3.90 & 0.16 & 3.93 & 0.16 \\
\hline 3 & 5.31 & 0.26 & 5.32 & 0.26 \\
\hline 4 & 4.10 & 0.19 & 4.17 & 0.20 \\
\hline 5 & 5.31 & 0.25 & 5.13 & 0.24 \\
\hline 6 & 4.91 & 0.24 & 4.93 & 0.24 \\
\hline 7 & 5.18 & 0.24 & 5.28 & 0.25 \\
\hline 8 & 5.41 & 0.26 & 5.32 & 0.26 \\
\hline 9 & 3.26 & 0.14 & 3.11 & 0.14 \\
\hline 10 & 4.83 & 0.22 & 4.74 & 0.23 \\
\hline 11 & 5.45 & 0.27 & 5.32 & 0.26 \\
\hline 12 & 3.74 & 0.21 & 3.99 & 0.22 \\
\hline 13 & 3.86 & 0.19 & 3.75 & 0.19 \\
\hline 14 & 4.46 & 0.21 & 4.33 & 0.21 \\
\hline 15 & 5.22 & 0.25 & 5.32 & 0.26 \\
\hline 16 & 5.18 & 0.26 & 5.32 & 0.26 \\
\hline 17 & 4.27 & 0.16 & 4.36 & 0.17 \\
\hline 18 & 5.36 & 0.25 & 5.32 & 0.26 \\
\hline 19 & 4.92 & 0.23 & 4.91 & 0.22 \\
\hline 20 & 2.91 & 0.14 & 2.97 & 0.14 \\
\hline
\end{tabular}

TABLE 3: ANOVA of the fitted quadratic polynomial model for the extraction yield of RU.

\begin{tabular}{|c|c|c|c|c|c|c|}
\hline Source & Sum of squares & Degrees of freedom $(\mathrm{df})$ & Mean squares & $F$ value & $P$ value & Remarks \\
\hline Model & 11.20 & 9 & 1.24 & 51.71 & $<0.0001$ & Significant \\
\hline$X_{1}$ & 4.61 & 1 & 4.61 & 191.70 & $<0.0001$ & Significant \\
\hline$X_{2}$ & 0.36 & 1 & 0.36 & 15.05 & 0.0031 & \\
\hline$X_{3}$ & 1.58 & 1 & 1.58 & 65.53 & $<0.0001$ & Significant \\
\hline$X_{1} X_{2}$ & 0.027 & 1 & 0.027 & 1.13 & 0.3129 & \\
\hline$X_{1} X_{3}$ & 0.0068 & 1 & 0.0068 & 0.28 & 0.6071 & \\
\hline$X_{2} X_{3}$ & 0.081 & 1 & 0.081 & 3.38 & 0.0959 & \\
\hline$X_{1}^{2}$ & 3.38 & 1 & 3.38 & 140.34 & $<0.0001$ & Significant \\
\hline$X_{2}^{2}$ & 0.85 & 1 & 0.85 & 35.40 & 0.0001 & \\
\hline$X_{3}^{2}$ & 1.04 & 1 & 1.04 & 43.04 & $<0.0001$ & Significant \\
\hline Residual & 0.24 & 10 & 0.024 & & & \\
\hline Lack of fit & 0.19 & 5 & 0.037 & 3.33 & 0.1065 & Not significant \\
\hline Pure error & 0.056 & 5 & 0.011 & & & \\
\hline Cor. total & 11.44 & 19 & & & & \\
\hline
\end{tabular}

$F$-value was 2.48 , and the $P$ value $(0.1711)$ was greater than 0.05 indicating that the lack of fit was not significant relative to the pure error.

3.3. Optimization Analysis. The interaction between the variables was shown in Figure 6 and it can be seen from Figure 6 that the $3 \mathrm{D}$ response surfaces show that, at high levels of microwave power and an extraction time at a constant ratio of plant material to solvent, the extraction yield was maximal. The optimum extraction conditions (independent variables) proposed by DE software were as follows: extraction time of $12.27 \mathrm{~min}$, liquid-solid ratio of $31.78 \mathrm{~mL} / \mathrm{g}$, and microwave power of $533.87 \mathrm{~W}$. The predicted extraction yield under the above conditions was computed as $5.58 \mathrm{mg}$ RU and $0.27 \mathrm{mg}$ QU per $1 \mathrm{~g}$ of dried plant material. Considering the precision 
TABLE 4: ANOVA of the fitted quadratic polynomial model for the extraction yield of QU.

\begin{tabular}{|c|c|c|c|c|c|c|}
\hline Source & Sum of squares & Degrees of freedom (df) & Mean squares & $F$ value & $P$ value & Remarks \\
\hline Model & 0.034 & 9 & 0.037 & 51.13 & $<0.0001$ & Significant \\
\hline$X_{1}$ & 0.012 & 1 & 0.012 & 158.99 & $<0.0001$ & Significant \\
\hline$X_{2}$ & $3.312 \times 10^{-3}$ & 1 & $3.312 \times 10^{-3}$ & 45.26 & $<0.0001$ & Significant \\
\hline$X_{3}$ & $9.458 \times 10^{-4}$ & 1 & $9.458 \times 10^{-4}$ & 12.92 & 0.0049 & \\
\hline$X_{1} X_{2}$ & $3.314 \times 10^{-4}$ & 1 & $3.314 \times 10^{-4}$ & 4.53 & 0.0592 & \\
\hline$X_{1} X_{3}$ & $6.561 \times 10^{-5}$ & 1 & $6.561 \times 10^{-5}$ & 0.90 & 0.3660 & \\
\hline$X_{2} X_{3}$ & $5.246 \times 10^{-5}$ & 1 & $5.246 \times 10^{-5}$ & 0.72 & 0.4170 & \\
\hline$X_{1}^{2}$ & $9.950 \times 10^{-3}$ & 1 & $9.950 \times 10^{-3}$ & 135.98 & $<0.0001$ & Significant \\
\hline$X_{2}^{2}$ & $8.527 \times 10^{-3}$ & 1 & $8.527 \times 10^{-3}$ & 116.53 & $<0.0001$ & Significant \\
\hline$X_{3}^{2}$ & $1.588 \times 10^{-3}$ & 1 & $1.588 \times 10^{-3}$ & 21.70 & 0.0009 & \\
\hline Residual & $7.317 \times 10^{-4}$ & 10 & $7.317 \times 10^{-5}$ & & & \\
\hline Lack of fit & $5.213 \times 10^{-4}$ & 5 & $1.043 \times 10^{-4}$ & 2.48 & 0.1711 & Not significant \\
\hline Pure error & $2.105 \times 10^{-4}$ & 5 & $4.209 \times 10^{-5}$ & & & \\
\hline Cor. total & 0.034 & 19 & & & & \\
\hline
\end{tabular}

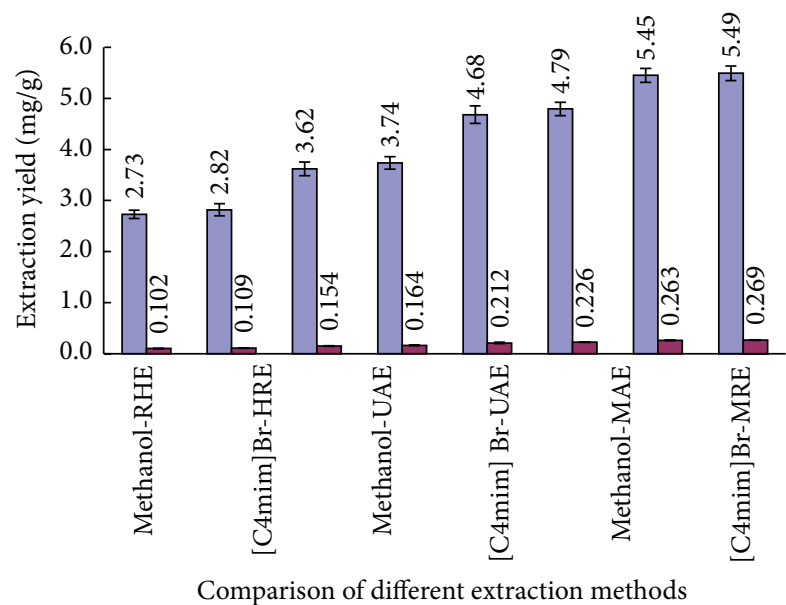

$\square$ Rutin

- Quercetin

FIGURE 7: Effect of different extraction methods on yield of RU and QU. Error bars indicate standard deviation $(n=3)$.

of extraction device, the optimal condition for extracting RU and QU was selected as extraction time $12 \mathrm{~min}$, liquid-solid ratio $32 \mathrm{~mL} / \mathrm{g}$, and microwave power of $534 \mathrm{~W}$. Under the above optimized condition, sample was repeatedly extracted for 6 times, the extraction yields were $5.67 \pm 0.12 \mathrm{mg} / \mathrm{g}$ for $\mathrm{RU}$ and $0.29 \pm 0.01 \mathrm{mg} / \mathrm{g}$ for QU (the extraction yield values corresponded to the $100 \%$ yield values); sample was extracted once, the extraction yields were $5.49 \pm 0.16 \mathrm{mg} / \mathrm{g}$ for RU and $0.27 \pm 0.01 \mathrm{mg} / \mathrm{g}$ for QU, and the yields of RU and QU were, respectively, $96.8 \%$ and $94.2 \%$.

3.4. Comparison of Different Extraction Procedures. A comparison between UMAE and the HRE, UAE, and MAE was performed and the results were seen in Figure 7.

Figure 7 shows that, for any method, it is worth noting that $[\mathrm{C} 4 \mathrm{mim}] \mathrm{Br}$ and methanol were almost the same as the extraction yields of two target compounds. However, methanol was volatile, flammable, and harmful to human and environment. Therefore, $[\mathrm{C} 4 \mathrm{mim}] \mathrm{Br}$ was chosen as extraction solvent in this study.

It can be seen from that the extraction yield of RU and QU obtained by ILs-UMAE was, respectively, $5.49 \mathrm{mg} / \mathrm{g}$ for RU and $0.27 \mathrm{mg} / \mathrm{g}$ for QU, which increased, respectively, 2.01-fold and 2.34-fold compared to conventional methanol-HRE. In conclusion, compared with other three extraction methods, ILs-UMAE had the highest extraction yield of RU and QU from the leaves of velvetleaf with the shortest extracting time. For UMAE, cavitation and microwave irradiation resulted in high effective temperatures and pressures at the interphase between solvent and solid matrix; moreover, microwaves raise the temperature suddenly and disrupt the structure of vegetal cell [34].

3.5. Quantitative Analysis by HPLC. Under the chromatographic conditions of 2.5, the peaks of RU and QU were observed with an acceptable resolution from the peaks of neighboring compounds. The HPLC chromatograms of the analyzed extracts are shown in Figure 8. Furthermore, recoveries were evaluated by standard-addition method, and the extracts were spiked with known quantities of standards. Results showed that the recoveries were in the range of 97.62$102.36 \%$ for the RU and $97.33-102.21 \%$ for QU with RSDs lower than $3.2 \%$ under the optimized UMAE conditions. The reproducibility and recovery proved that the present method was credible.

\section{Conclusion}

In the present study, the ILs-UMAE was used to extract the two objective compounds (RU and QU) from leaves of velvetleaf. According to the single factors experiments and CCD test, we concluded the optimized extraction solvent $2.00 \mathrm{M}\left[\mathrm{C}_{4} \mathrm{mim}\right] \mathrm{Br}$, extraction temperature $60^{\circ} \mathrm{C}$, extraction time $12 \mathrm{~min}$, liquid-solid ratio $32 \mathrm{~mL} / \mathrm{g}$, microwave power 


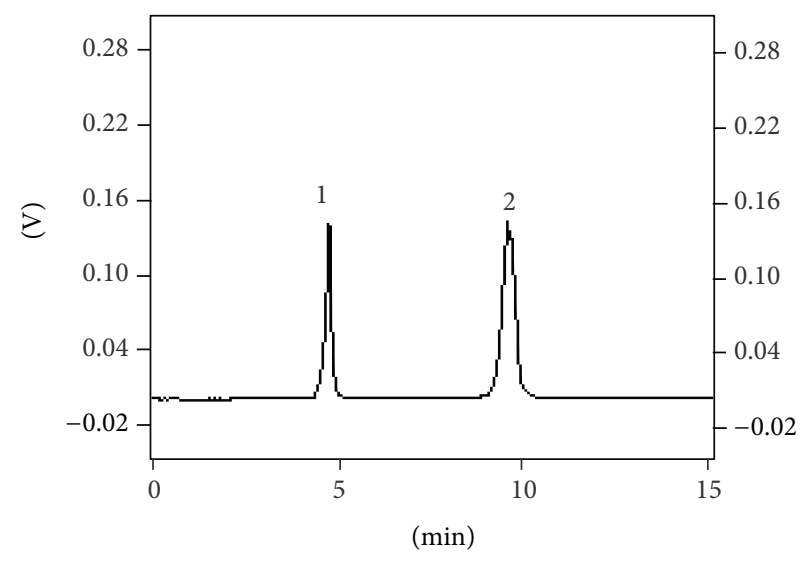

(a)

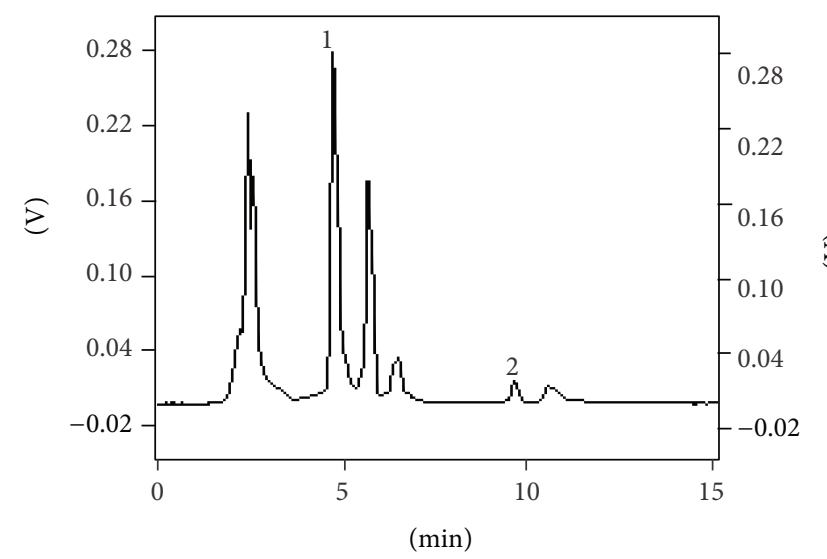

(b)

FIGURE 8: Chromatograms of RU and QU standard mixture (a), sample (b), Peak 1 for RU, and Peak 2 for QU under optimal conditions.

of $534 \mathrm{~W}$, and a fixed ultrasonic power of $50 \mathrm{~W}$. The RU and QU extraction yields obtained by ILs-UMAE were, respectively, $5.49 \pm 0.16 \mathrm{mg} / \mathrm{g}$ and $0.27 \pm 0.01 \mathrm{mg} / \mathrm{g}$, which increased, respectively, 2.01-fold and 2.34-fold compared to conventional HRE. In addition to the higher extraction yields, the shorter extraction time was used in ILs-UMAE, which suggested that the IL-UMAE was a rapid and highly effective extraction method for the extraction of RU and QU from the leaves of velvetleaf. Therefore, considering the unique properties of ILs, the IL-UMAE method shows a great promising prospect to be developed as an environmental friendly, rapid, and efficient technique in the extraction of RU and QU from leaves of velvetleafand it can be a promising technique for the extraction of natural active compounds from the other plant.

\section{Conflict of Interests}

The authors declare that there is no conflict of interests regarding the publication of this paper.

\section{Acknowledgments}

This work was financially supported by the Fundamental Research Fund for Central Universities (DL12CA05, DL12EA01-04, and DL13CA06), the National Natural Science Foundation (31200478), the Natural Science Foundation of Heilongjiang Province (C201412), and China Postdoctoral Science Foundation funded Project (2013M530773).

\section{References}

[1] N. R. Spencer, "Velvetleaf, Abutilon theophrasti (Malvaceae), history and economic impact in the United States," Economic Botany, vol. 38, no. 4, pp. 407-416, 1984.

[2] L. A. Wymore, C. Poirier, A. K. Watson, and A. R. Gotlieb, "Colletotrichum coccodes, a potential bioherbicide for control of velvetleaf (Abutilon theophrasti)," Plant Disease, vol. 72, pp. 534-538, 1988.

[3] Z. Amsellem, B. A. Cohen, and J. Gressel, "Engineering hypervirulence in a mycoherbicidal fungus for efficient weed control," Nature Biotechnology, vol. 20, no. 10, pp. 1035-1039, 2002.

[4] T. Nakaoki, N. Morita, A. Hiraki, and Y. Kurokawa, "Components of the Leaves of Lotus corniculatus L. var. japonicus Regel., Mikrolespedeza striata Makino, Magnolia obovata Thunb., and Abutilon avicennae Gaertn," Yakugaku Zasshi, vol. 76, pp. 347349, 1956.

[5] H. Wagner, M. A. Iyengar, and L. Hörhammer, "Flavonoids in Lespedeza capitata," Phytochemistry, vol. 11, no. 4, pp. 1518-1519, 1972.

[6] P. V. Sharma and Z. A. Ahmad, "Two sesquiterpene lactones from Abutilon indicum," Phytochemistry, vol. 28, no. 12, p. 3525, 1989.

[7] N. Russo, M. Toscano, and N. Uccella, "Semiempirical molecular modeling into quercetin reactive site: structural, conformational, and electronic features," Journal of Agricultural and Food Chemistry, vol. 48, no. 8, pp. 3232-3237, 2000.

[8] J. F. M. Post and R. S. Varma, "Growth inhibitory effects of bioflavonoids and related compounds on human leukemic CEM-C1 and CEM-C7 cells," Cancer Letters, vol. 67, no. 2-3, pp. 207-213, 1992.

[9] P. Jiang, F. Burczynski, C. Campbell, G. Pierce, J. A. Austria, and C. J. Briggs, "Rutin and flavonoid contents in three buckwheat species Fagopyrum esculentum, F. tataricum, and F. homotropicum and their protective effects against lipid peroxidation," Food Research International, vol. 40, no. 3, pp. 356-364, 2007.

[10] A. A. Elzaawely, T. D. Xuan, and S. Tawata, "Essential oils, kava pyrones and phenolic compounds from leaves and rhizomes of Alpinia zerumbet (Pers.) B.L. Burtt. \& R.M. Sm. and their antioxidant activity," Food Chemistry, vol. 103, no. 2, pp. 486494, 2007.

[11] T. Suzuki, Y. Honda, and Y. Mukasa, "Effects of UV-B radiation, cold and desiccation stress on rutin concentration and rutin glucosidase activity in tartary buckwheat (Fagopyrum tataricum) leaves," Plant Science, vol. 168, no. 5, pp. 1303-1307, 2005.

[12] C. N. A. Leong, M. Tako, I. Hanashiro, and H. Tamaki, "Antioxidant flavonoid glycosides from the leaves of Ficus pumila L.," Food Chemistry, vol. 109, no. 2, pp. 415-420, 2008.

[13] Y. Han, "Rutin has therapeutic effect on septic arthritis caused by Candida albicans," International Immunopharmacology, vol. 9, no. 2, pp. 207-211, 2009. 
[14] S. Umar, N. K. Mishra, K. Pal et al., "Protective effect of rutin in attenuation of collagen-induced arthritis in Wistar rat by inhibiting inflammation and oxidative stress," Indian Journal of Rheumatology, vol. 7, no. 4, pp. 191-198, 2012.

[15] R. Dall'Agnol, A. Ferraz, A. P. Bernardi et al., "Antimicrobial activity of some Hypericum species," Phytomedicine, vol. 10, no. 6-7, pp. 511-516, 2003.

[16] W. Ren, Z. Qiao, H. Wang, L. Zhu, and L. Zhang, "Flavonoids: promising anticancer agents," Medicinal Research Reviews, vol. 23, no. 4, pp. 519-534, 2003.

[17] C. H. Jung, J. Y. Lee, C. H. Cho, and C. J. Kim, "Anti-asthmatic action of quercetin and rutin in conscious guinea-pigs challenged with aerosolized ovalbumin," Archives of Pharmacal Research, vol. 30, no. 12, pp. 1599-1607, 2007.

[18] D. T. Veličković, M. T. Nikolova, S. V. Ivancheva, J. B. Stojanović, and V. B. Veljković, "Extraction of flavonoids from garden (Salvia officinalis L.) and glutinous (Salvia glutinosa L.) sage by ultrasonic and classical maceration," Journal of the Serbian Chemical Society, vol. 72, no. 1, pp. 73-80, 2007.

[19] D. Grigonis, P. R. Venskutonis, B. Sivik, M. Sandahl, and C. S. Eskilsson, "Comparison of different extraction techniques for isolation of antioxidants from sweet grass (Hierochloë odorata)," Journal of Supercritical Fluids, vol. 33, no. 3, pp. 223-233, 2005.

[20] J. S. Wilkes, "A short history of ionic liquids-from molten salts to neoteric solvents," Green Chemistry, vol. 4, no. 2, pp. 73-80, 2002.

[21] A. Berthod, M. J. Ruiz-Ángel, and S. Carda-Broch, "Ionic liquids in separation techniques," Journal of Chromatography A, vol. 1184, no. 1-2, pp. 6-18, 2008.

[22] C. F. Poole and S. K. Poole, "Extraction of organic compounds with room temperature ionic liquids," Journal of Chromatography A, vol. 1217, no. 16, pp. 2268-2286, 2010.

[23] Z. Wei, Y. Zu, Y. Fu et al., "Ionic liquids-based microwaveassisted extraction of active components from pigeon pea leaves for quantitative analysis," Separation and Purification Technology, vol. 102, pp. 75-81, 2013.

[24] L. J. Zhang, Y. L. Geng, W. J. Duan, D. J. Wang, M. R. Fu, and $\mathrm{X}$. Wang, "Ionic liquid-based ultrasound-assisted extraction of fangchinoline and tetrandrine from Stephaniae tetrandrae," Journal of Separation Science, vol. 32, no. 20, pp. 3550-3554, 2009.

[25] T. D. Chermenskaya, E. A. Stepanycheva, A. V. Shchenikova, E. I. Savelieva, and A. S. Chakaeva, "Insecticidal effects of Ungernia severtzovii bulb extracts against the grain aphid Schizaphis graminum (Rondani)," Industrial Crops and Products, vol. 36, no. 1, pp. 122-126, 2012.

[26] S.-S. Hu, L. Yi, X.-Y. Li et al., "Ionic liquid-based one-step micellar extraction of multiclass polar compounds from hawthorn fruits by ultrahigh-performance liquid chromatography coupled with quadrupole time -of-flight tandem mass spectrometry," Journal of Agricultural and Food Chemistry, vol. 62, no. 23, pp. 5275-5280, 2014.

[27] W. Y. Ma, Y. B. Lu, R. L. Hu, J. H. Chen, Z. Z. Zhang, and Y. J. Pan, "Application of ionic liquids based microwave-assisted extraction of three alkaloids $\mathrm{N}$-nornuciferine, $\mathrm{O}$-nornuciferine, and nuciferine from lotus leaf," Talanta, vol. 80, no. 3, pp. 12921297, 2010.

[28] C. Chan, R. Yusoff, G. Ngoh, and F. W. Kung, "Microwaveassisted extractions of active ingredients from plants," Journal of Chromatography A, vol. 1218, no. 37, pp. 6213-6225, 2011.

[29] P. Sun and D. W. Armstrong, "Ionic liquids in analytical chemistry," Analytica Chimica Acta, vol. 661, no. 1, pp. 1-16, 2010.
[30] Y. Jiao and Y. Zuo, "Ultrasonic extraction and HPLC determination of anthraquinones, aloe-emodine, emodine, rheine, chrysophanol and physcione, in roots of Polygoni multiflori," Phytochemical Analysis, vol. 20, no. 4, pp. 272-278, 2009.

[31] S. Matsumoto, R. M. Varela, M. Palma et al., "Bio-guided optimization of the ultrasound-assisted extraction of compounds from Annona glabra L. leaves using the etiolated wheat coleoptile bioassay," Ultrasonics Sonochemistry, vol. 21, no. 4, pp. 1578-1584, 2014.

[32] Y. Zheng, Y. Li, and W. D. Wang, "Optimization of ultrasonicassisted extraction and in vitro antioxidant activities of polysaccharides from Trametes orientalis," Carbohydrate Polymers, vol. 111, pp. 315-323, 2014.

[33] Z. Lou, H. Wang, S. Zhu, S. Chen, M. Zhang, and Z. Wang, "Ionic liquids based simultaneous ultrasonic and microwave assisted extraction of phenolic compounds from burdock leaves," Analytica Chimica Acta, vol. 716, pp. 28-33, 2012.

[34] S. Chemat and E. D. C. Esveld, "Contribution of microwaves or ultrasonics on carvone and limonene recovery from dill fruits (Anethum graveolens L.)," Innovative Food Science and Emerging Technologies, vol. 17, pp. 114-119, 2013.

[35] Z. A. Ghani, M. A. M. Ishak, and K. Ismail, "Direct liquefaction of Mukah Balingian lorank Malaysian coal: optimization using response surface methodology," Asia-Pacific Journal of Chemical Engineering, vol. 6, no. 4, pp. 581-588, 2011.

[36] J. G. Huddleston, A. E. Visser, W. M. Reichert, H. D. Willauer, G. A. Broker, and R. D. Rogers, "Characterization and comparison of hydrophilic and hydrophobic room temperature ionic liquids incorporating the imidazolium cation," Green Chemistry, vol. 3, no. 4, pp. 156-164, 2001.

[37] S. Chun, S. V. Dzyuba, and R. A. Bartsch, "Influence of structural variation in room-temperature ionic liquids on the selectivity and efficiency of competitive alkali metal salt extraction by a crown ether," Analytical Chemistry, vol. 73, no. 15, pp. 3737-3741, 2001.

[38] J. J. Wang, Y. C. Pei, Y. Zhao, and Z. G. Hu, "Recovery of amino acids by imidazolium based ionic liquids from aqueous media," Green Chemistry, vol. 7, no. 4, pp. 196-202, 2005.

[39] J. L. Anderson, J. Ding, T. Welton, and D. W. Armstrong, "Characterizing ionic liquids on the basis of multiple solvation interactions," Journal of the American Chemical Society, vol. 124, no. 47, pp. 14247-14254, 2002.

[40] Z. Guo, B. Lue, K. Thomasen, A. S. Meyer, and X. Xu, "Predictions of flavonoid solubility in ionic liquids by COSMO-RS: experimental verification, structural elucidation, and solvation characterization," Green Chemistry, vol. 9, no. 12, pp. 1362-1373, 2007.

[41] L. Crowhurst, P. R. Mawdsley, J. M. Perez-Arlandis, P. A. Salter, and T. Welton, "Solvent-solute interactions in ionic liquids," Physical Chemistry Chemical Physics, vol. 5, no. 13, pp. 27902794, 2003.

[42] D. C. Montgomery, Design and Analysis of Experiment, John Wiley \& Sons, New York, NY, USA, 5th edition, 2001.

[43] W. Kong, S. Hua, H. Cao et al., "Optimization of mixotrophic medium components for biomass production and biochemical composition biosynthesis by Chlorella vulgaris using response surface methodology," Journal of the Taiwan Institute of Chemical Engineers, vol. 43, no. 3, pp. 360-367, 2012. 

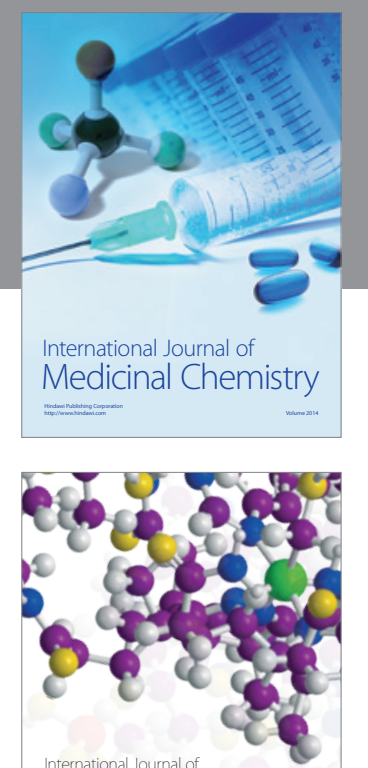

\section{Carbohydrate} Chemistry

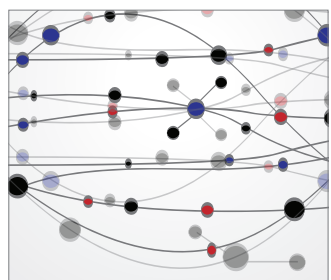

The Scientific World Journal
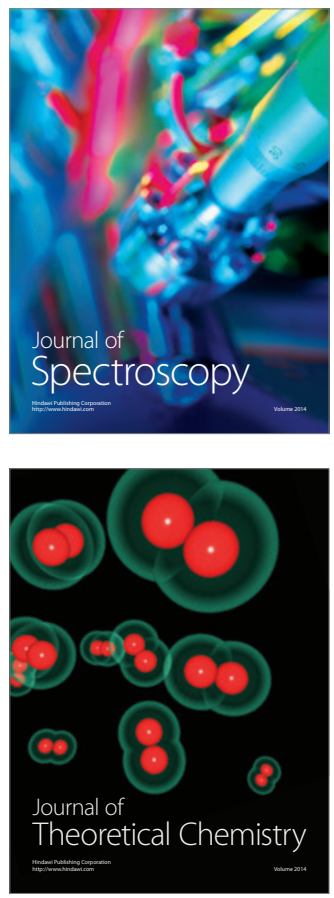
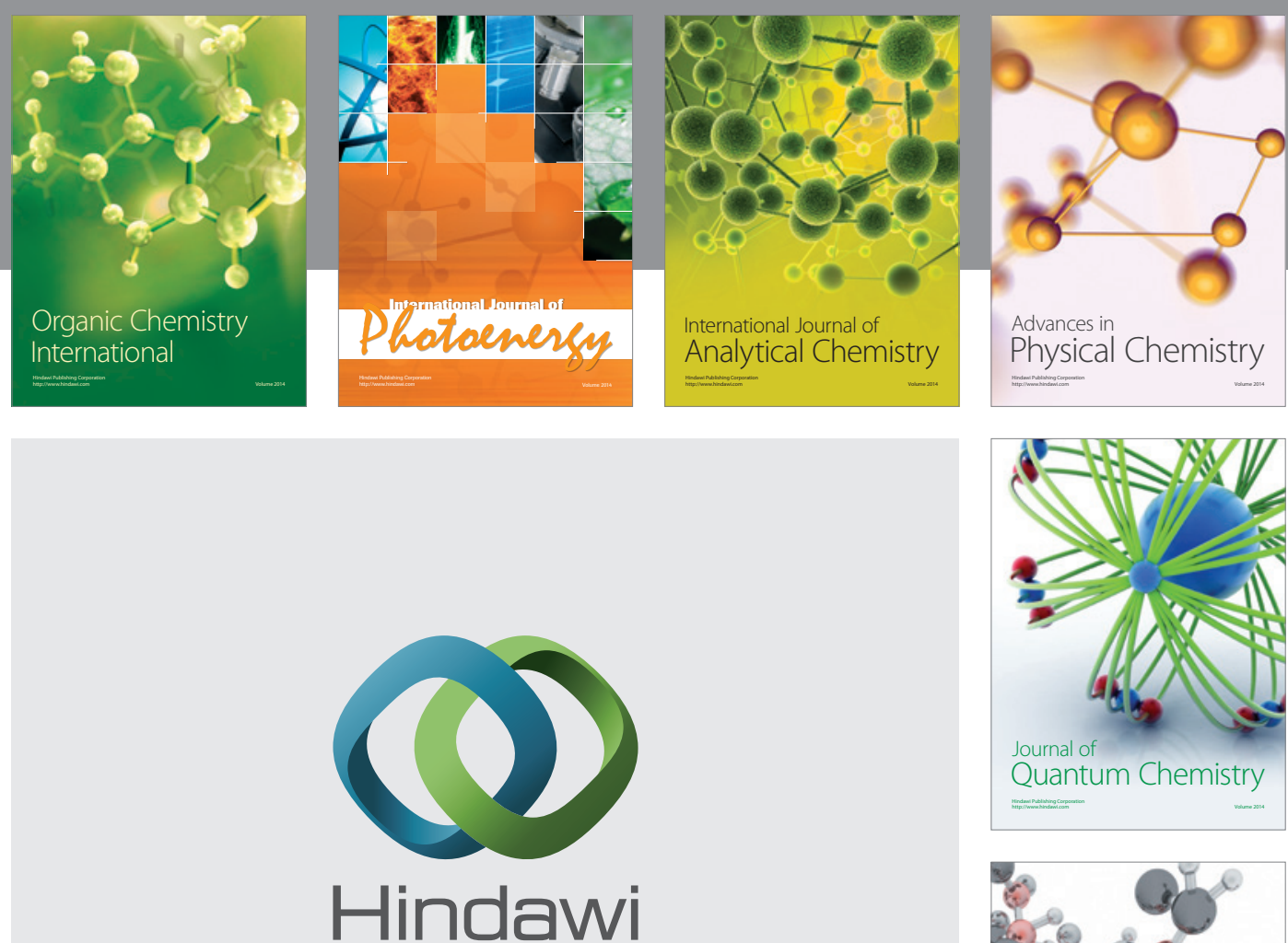

Submit your manuscripts at

http://www.hindawi.com

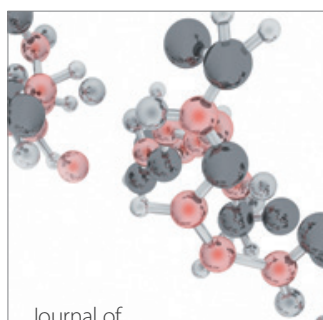

Analytical Methods

in Chemistry

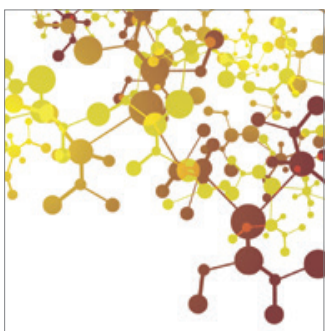

Journal of

Applied Chemistry

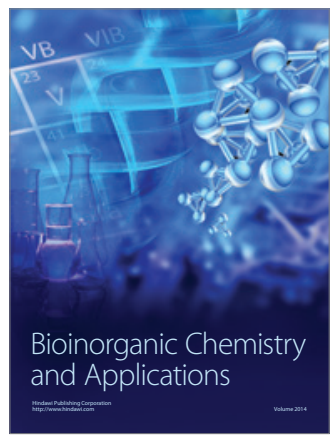

Inorganic Chemistry
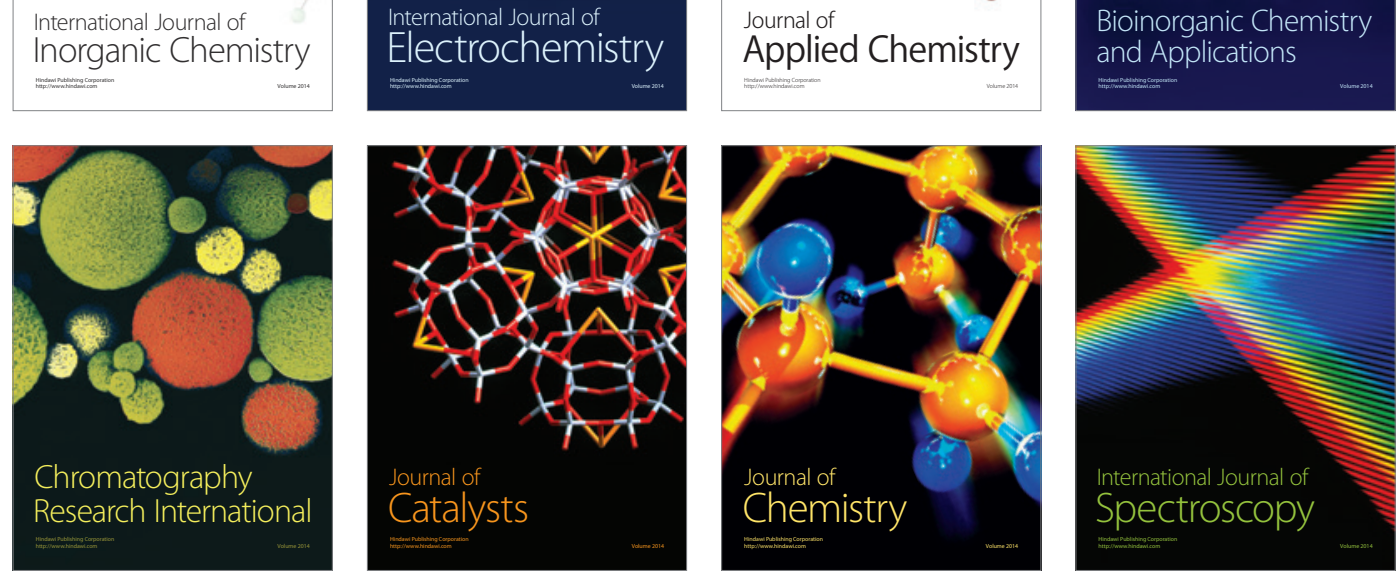